\title{
TRAJETÓRIA HISTÓRICA DO ESTÁGIO CURRICULAR NA GRADUAÇÃO EM ENFERMAGEM NO BRASIL: DILEMAS E TENSÕES*
}

\author{
Larissa Sapucaia Ferreira Esteves ${ }^{1}$, Isabel Cristina Kowal Olm Cunha ${ }^{2}$, Elena Bohomol ${ }^{3}$,Vanessa Ribeiro \\ Neves $^{4}$
}

\begin{abstract}
RESUMO: Objetivo: descrever e analisar a trajetória histórica da legislação que sustenta o ensino de graduação em Enfermagem no Brasil, com foco no desenvolvimento do Estágio Curricular desde o princípio da formação profissional até os dias atuais. Método: estudo qualitativo, de natureza histórica, que utilizou a análise documental como abordagem. Os dados foram coletados entre fevereiro e abril de 2017. As fontes primárias dos dados foram leis, decretos, resoluções e pareceres oficiais de órgãos federais e da profissão, no período de 1890 a 2017. Resultados: foram identificados 21 documentos oficiais que regulamentaram a trajetória histórica do ensino superior em Enfermagem e do estágio curricular.A intencionalidade dos estágios passou por profundas modificações ao longo da história, partindo da oferta de mão de obra para momento de edificação de competências profissionais. Conclusão: embora haja disputas entre o campo da formação e o mundo do trabalho, há que se ponderar que não se trata de forças contrárias, mas de sistemas que se complementam.
\end{abstract}

DESCRITORES: Estágios; Educação superior; Enfermagem;Educação em enfermagem; História da enfermagem.

\section{HISTORICAL TRAJECTORY OF CURRICULAR TRAINING IN BRAZILIAN UNDERGRADUATE NURSING PROGRAMS: DILEMMAS AND TENSIONS}

\begin{abstract}
Objective:describe and analyze the historical trajectory of the legislation underlying undergraduate Nursing education in Brazil, focusing on the development of the Curricular Trainingfrom the start of vocational education until today.Method:qualitative and historical study using documentary analysis. The data were collected between February and April 2017. The primary data sources were laws, decrees, resolutions and official opinions of federal and professional entities issued between 1890 and 2017. Results:twenty-one official documents were identified that regulated the historical trajectory of higher Nursing education and curricular training. The intentionality of the traineeships underwent profound changes in the course of history, from the supply of workforce to professional competency building.Conclusion:despite disputes between the educational sphere and the job world, it should be weighted that these are not contrary but complementary systems.

DESCRIPTORS: Traineeships; Education, Higher;Nursing;Education, Nursing; History of Nursing.
\end{abstract}

\section{TRAYECTORIA HISTÓRICA DE LA PASANTÍA CURRICULAR EN LA EDUCACIÓN DE PREGRADO EN ENFERMERÍA EN BRASIL: DILEMAS Y TENSIONES}

RESUMEN: Objetivo: describir y analizar la trayectoria histórica de la legislación que soporta la enseñanza de pregrado en Enfermería en Brasil, con foco en el desarrollo de la Pasantía Curricular desde el principio de la formación profesional hasta los días actuales. Método: estudio cualitativo, del tipo histórico, que utilizó el análisis documental como aproximación. Los datos fueron recolectados entre febrero y abril del 2017. Las fuentes primarias de los datos fueron leyes, decretos, resoluciones y opiniones oficiales de entidades federales y profesionales, en el período desde 1890 hasta 2017. Resultados: fueron identificados 21 documentos oficiales que regularon la trayectoria histórica de la educación superior en Enfermería y de la pasantía curricular. La intencionalidad de las pasantías pasó por modificaciones profundas a lo largo de la historia, avanzando desde la oferta de mano de obra hacia la construcción de competencias profesionales. Conclusión: a pesar de disputas entre el campo de la formación y el mundo del trabajo, se debe ponderar que no se trata de fuerzas contrarias, pero de sistemas complementarios.

DESCRIPTORES: Pasantías; Educación Superior; Enfermería; Educación en Enfermería; Historia de la enfermería.

\footnotetext{
*Artigo extraído da tese de doutorado "Estágio Curricular Supervisionado: o retrato do ensino no estado de São Paulo". Universidade Federal de São Paulo, 2018.

${ }^{1}$ Enfermeira. Doutoranda em Enfermagem. Docente da Universidade do Oeste Paulista. São Paulo, SP, Brasil.

${ }^{2}$ Enfermeira. Livre Docente. Docente Aposentada de Enfermagem da Universidade Federal de São Paulo. São Paulo, SP, Brasil. ${ }^{3}$ Enfermeira. Livre Docente. Docente de Enfermagem da Universidade Federal de São Paulo. São Paulo, SP, Brasil.

${ }^{4}$ Enfermeira. Doutora em Ciências. Docente de Enfermagem da Universidade Federal de São Paulo. São Paulo, SP, Brasil.
}

Autor Correspondente:

Larissa Sapucaia Ferreira Esteves

Universidade Federal de São Paulo

R. José Tarifa Conde, 334 - 19020540 -Presidente Prudente, SP, Brasil

E-mail: larissasapucaiaesteves@gmail.com
Recebido: 21/02/2018

Finalizado: $28 / 09 / 2018$ 


\section{- INTRODUÇÃO}

Por muito tempo, a assistência de enfermagem não foi pensada como tendo por base um conjunto de conhecimentos teóricos, mas apenas como um conjunto de vivências práticas, e muitas vezes completamente desarticulado da teoria.A supervisão, muitas vezes, era realizada por outros profissionais não enfermeiros. Muitas escolas foram implantadas no Brasil apenas com o objetivo de baratear a assistência hospitalar, explorando o trabalho prático e não remunerado dos estudantes ${ }^{(1-3)}$.

Desde 1988, a população brasileira tem presenciado o fortalecimento de políticas, programas e ações de saúde propostas pelo Sistema Único de Saúde (SUS) por meio da implementação permanente de estratégias inovadoras. A consolidação prática dos princípios doutrinários e organizativos que orientam o SUS vem provocando uma série de transformações na forma com que são ofertados os cuidados em saúde, gerando inquietações por parte dos aparelhos formadores ${ }^{(4)}$.

A formação de massa crítica profissional capaz de compreender com profundidade os princípios e diretrizes do SUS é condição para garantir a robustez das ações de saúde e o avanço na efetivação da integralidade, humanização, promoção e vigilância na atenção à saúde ${ }^{(1)}$. Para tanto, o alinhamento entre os setores saúde e educação foi assinalado pela Constituição Federal, Art. 200, que define que compete ao SUS “ordenar a formação de recursos humanos na área da saúde"

Nessa perspectiva, não há como assegurar a construção doSistema Único de Saúde sem considerar a fundo a natureza do processo formativo. Os meios e métodos de ensino-aprendizagem que buscam aproximar e inserir o futuro profissional no mundo concreto do trabalho em saúde se constituem como estratégias para garantir a implementação e efetivação das políticas de saúde tal como foram idealizadas $^{(2)}$ e este momento de inserção na prática profissional possui diferentes conceitos e significados ao longo da história.

As atividades clínicas desenvolvidas em serviços de saúde não possuem a mesma categoria de Estágio Curricular Supervisionado (ECS). A interpretação equivocada que inclui qualquer prática clínica como sendo ECS sustenta a permanênciade antigos modelos de ensino, numa aparenteadequação às novas diretrizes ${ }^{(6)}$.

O ECS possui características de terminalidade do processo formativo e pode trazer importante contribuiçãoeducacionalaos enfermeiros, sendo estratégia de real impacto na formação profissional, desde que inserido em uma estrutura curricular que garanta anteriormente tanto práticas clínicas de disciplinas específicas, quanto atividades que visem aproximar o aluno do exercício profissional em cenários diversificados ${ }^{(3,6)}$.

Diante do potencial articulador e formador do ECS, as Diretrizes Curriculares Nacionais (DCN) para os Cursos de Graduação em Saúde apresentamessa etapa como componente obrigatório do último ano da formação e determinam que, na Enfermagem, essa etapa deva ser desenvolvida em, no mínimo, $20 \%$ da carga horária total do curso $^{(7)}$.

Para a realização do ECS, as DCN asseguram a participação efetiva dos enfermeiros que atuam nos serviços de saúde ${ }^{(7)}$, como um elo de comunicação e cooperação entre o ensino e o mundo do trabalho. A concepção do ECS como recurso pedagógico com base na ação-reflexão-ação sobre as situações vivenciadas pelo estudanteé relativamente nova, e experiências anteriores foram marcadas por inúmeras tensões ao longo da história.

Originariamente, o estagiário era pensado mais como fornecedor de mão de obra do que etapa pedagógica na formação do futuro profissional. Ao longo do tempo, passou a ser questionado pela comunidade acadêmica, por meio de debates e lutas, e entendido como momento estratégico de transformação das práticas laborativas e assim constituir-se como parte do arsenal metodológico do processo educacional, na busca por novos perfis de trabalhadores ${ }^{(3)}$.

Embora esteja claro nas DCN que o ECS deva ser um dos elementos fundamentais para a formação acadêmica e a ideia de desenvolver o ensino nos serviços de saúdeesteja presente nos currículos desde a fundação das primeiras escolas de Enfermagem, a concepção de ECS ainda não é consenso nas organizações curriculares, e tampouco nos debates fomentados pelas entidades representantes da classe, produzindo reflexos negativos para a formação do enfermeiro ${ }^{(2)}$.

http://dx.doi.org/10.5380/ce.v23i4.58024 
Sendo assim, neste estudo, tem-se o objetivo de descrever e analisar a trajetória histórica da legislação que sustenta o ensino de graduação em Enfermagem no Brasil, com foco nodesenvolvimento do Estágio Curricular (EC) realizado desde o princípio da formação profissional até receber a denominação e a intencionalidade atual de Estágio Curricular Supervisionado (ECS).

\section{- MÉTODO}

Estudo qualitativo, com a pesquisa histórica como método, visando analisar origens, fundamentos e trajetória histórica do EC na formação profissional de enfermeiros no Brasil ${ }^{(8)}$.

Utilizou-se a pesquisa documental, pois a proposta foi analisar documentos textuais que pudessem mostrar a trajetória histórica das diferentes concepções do EC na formação profissional de enfermeiros. Para tanto, foram seguidas as etapas: localização dos documentos oficiais que regulamentaram o ensino em Enfermagem no Brasil, desde 1890; leitura minuciosa dos achados, reunindo aqueles que continham informações acerca das formas de estágios durante a graduação em Enfermagem; e, por fim, análise dos documentos encontrados para identificar as reais intencionalidades do estágio na graduação em Enfermagem até culminar na obrigatoriedade da implantação do $\operatorname{ECS}^{(8)}$.

A coleta de dados foi realizada entre fevereiro e abril de 2017 nas bases de dados oficiais do governo brasileiro, dentre as quais: Casa Civil, Ministério da Educação, Ministério da Saúde, Ministério do Trabalho, e nas bases de dados do Conselho Federal de Enfermagem (COFEN) e da Associação Brasileira de Enfermagem (ABEn). Para a busca documental, as palavras chaves leis, legislação, resolução, portaria, parecer foram utilizadas em combinação com o descritor enfermagem. Foram excluídos aqueles que não versavam sobre o ensino em enfermagem no Brasil, que não abordavam a temática Estágio Curricular e que não se encontravam disponíveis na íntegra. Os documentos elegidos para compor a revisão foram leis, decretos, resoluções, portarias e pareceres exarados a partir de 1890, considerado o ano de instituição do ensino de Enfermagem no Brasil.

Para organização dos dados, os autores construíram instrumento que continha ano da publicação, tipo de legislação, enunciado do objeto, determinação acerca do EC, intencionalidade do estágio no documento e órgão responsável pela publicação. Os documentos foram organizados em ordem cronológica. O conteúdo dos documentos foi compilado e os achados foram, então, discutidos à luz do contexto histórico de cada currículo e da literatura científica disponível sobre o tema.

\section{- RESULTADOS}

No período de 127 anos (1890-2017), foram identificados 21 documentos oficiais que narram a história do ensino da Enfermagem no Brasil: sete leis, cinco decretos, três resoluções do Conselho Nacional de Educação, quatro resoluções do COFEN, uma portaria do Ministério da Educação e um parecer da ABEn. Após a reunião do arsenal legislativo, foi possível identificar seis propostas curriculares diferentes para os cursos de Graduação em Enfermagem no Brasil, conforme apresenta a Tabela 1.

Tabela 1 - Referencial legislativo que orientou a formação profissional de enfermeiros no Brasil e o EC, no período de 1890 a 2017. São Paulo, SP, Brasil, 2017 (continua)

\begin{tabular}{|c|c|c|}
\hline ANO & LEGISLAÇÃO & ENUNCIADO DO OBJETO \\
\hline 1890 & $\begin{array}{l}\text { Decreto } \mathrm{n}^{\circ} .791 \text {, de } 27 \text { de setembro de } \\
1980^{(9)} \text {. }\end{array}$ & $\begin{array}{l}\text { Cria no Hospício Nacional de Alienados uma escola } \\
\text { profissional de enfermeiros e enfermeiras: } \mathbf{1}^{\mathbf{0}} \text { modelo de } \\
\text { currículo. }\end{array}$ \\
\hline 1923 & $\begin{array}{l}\text { Decreto } n^{\circ} .16 .300 \text {, de } 31 \text { de dezembro de } \\
1923^{(10)} \text {. }\end{array}$ & $\begin{array}{l}\text { Aprova o regulamento do Departamento Nacional de } \\
\text { Saúde Pública: } \mathbf{2}^{\mathbf{0}} \text { modelo de currículo. }\end{array}$ \\
\hline 1931 & Decreto $n^{\circ} .20 .109$, de 15 de junho de $1931^{(11)}$. & $\begin{array}{l}\text { Regula o exercício da enfermagem no Brasil e fixa as } \\
\text { condições para a equiparação das escolas de Enfermagem. }\end{array}$ \\
\hline
\end{tabular}


1932 Decreto $\mathrm{n}^{\circ}$. 21.141, de 10 de março de Aprova o regulamento para organização do quadro de $1932^{(12)}$. enfermeiros do Exército.

1948 Decreto $n^{\circ} .24 .768$, de 6 de abril de $1948^{(13)}$. Concede equiparação à escola de Enfermagem da Cruz Vermelha brasileira.

1949 Lei $\mathrm{n}^{\circ} .775$, de 06 de agosto de 1949 ${ }^{(14)}$. Dispõe sobre o ensino de Enfermagem no País e dá outras providências.

1961 Lei $n^{\circ}$. 4.024, de 20 de dezembro de 1961 ${ }^{(15)}$. Fixa as Diretrizes e Bases da Educação Nacional.

1962 Parecer $\mathrm{n}^{\circ} .271$, de 19 de outubro de $1962^{(16)}$. Estabelece o currículo mínimo para os cursos de graduação em Enfermagem no Brasil: $3^{\circ}$ modelo de currículo.

1968 Lei $\mathrm{n}^{\circ}$. 5.540, de 28 de novembro de $1968^{(17)}$. Fixa normas de organização e funcionamento do ensino superior e sua articulação com a escola médica, e dá outras providências.

1972 Resolução do Conselho Federal de Estabelece novo currículo mínimo para os cursos de Educação $n^{\circ}$. 4, de 25 de fevereiro de $1972^{(18)}$. graduação em Enfermagem no Brasil: $4^{\circ}$ modelo de currículo.

1977 Lei $\mathrm{n}^{\circ} .6 .494$, de 7 de dezembro de $1977^{(19)}$. Dispõe sobre os estágios de estudantes de estabelecimento de ensino superior e profissionalizante e dá outras providências.

1988 Leis $\mathrm{n}^{\circ} .8080$, de 19 de setembro de $1990^{(20)}$. Dispõe sobre as condições para a promoção, proteção e recuperação da saúde, a organização e o funcionamento dos serviços correspondentes e dá outras providências.

1994 Portaria do Ministério da Educação e do Fixa mínimo de conteúdo e duração do curso de graduação Desporto $\mathrm{n}^{\circ}$. 1721, de 1994 ${ }^{(21)}$. em Enfermagem: $5^{\mathbf{0}}$ modelo de currículo.

1996 Lei $\mathrm{n}^{\circ} .9 .394$, de 20 de dezembro de 1996 ${ }^{(22)}$. Estabelece as Diretrizes e Bases da Educação Nacional.

2001 Resolução Conselho Nacional de Educação, Institui as Diretrizes Curriculares Nacionais para os Cursos n .3 de 07 de novembro de 2001 ${ }^{(7)}$. de Graduação em Enfermagem: $6^{\circ}$ modelo de currículo.

2004 Resolução do Conselho Nacional de Estabelece Diretrizes Nacionais para a organização e a Educação $n^{\circ} .1$, de 21 de janeiro de 2004 ${ }^{(23)}$. realização de Estágio de alunos da Educação Profissional e do Ensino Médio, inclusive nas modalidades de Educação Especial e de Educação de Jovens e Adultos.

2005 Resolução do Conselho Federal de Dispõe sobre indicativos para a realização de estágio Enfermagem $n^{\circ}$. 299, de 16 de março de curricular supervisionado de estudantes de Enfermagem $2005^{(24)}$. de graduação e do nível técnico.

2008 Lei $\mathrm{n}^{\circ} .11788$, de 25 de setembro de 2008 ${ }^{(25)}$. Dispõe sobre o estágio de estudantes.

2010 Resolução do Conselho Federal de Dispõe sobre a supervisão do enfermeiro em estágio ou Enfermagem $n^{\circ} .371$, de 8 de setembro de quaisquer atividades práticas. $2010^{(26)}$.

2013 ResoluçãoConselhoFederal deEnfermagem Dispõe sobre a participação do enfermeiro na supervisão $\mathrm{n}^{\circ}$. 441, de 15 de maio de $2013^{(27)}$. de atividade prática e estágio supervisionado de estudantes dos diferentes níveis da formação profissional de Enfermagem.

2017 Resolução do Conselho Federal de Dispõe sobre o inciso II, do artigo $1^{\circ}$, da Resolução Cofen Enfermagem $n^{\circ}$. 539, de 07 de abril de $n^{\circ} .441 / 2013$.

$2017^{(28)}$.

Fonte: as autoras

\section{- DISCUSSÃO}

O decreto $\mathrm{n}^{\circ}$ 791, que cria, no Hospício Nacional de Alienados do Rio de Janeiro, uma escola profissional de enfermeiros e enfermeiras, apresenta o $\mathbf{1}^{\mathbf{0}}$ modelo de currículo para escolas de enfermagem no Brasil. Tal currículo continha as disciplinas essenciais para a formação do enfermeiro, sem determinar carga horáriaa cada uma delas. Estabelecia que o curso teórico,desenvolvido em dois anos, deveria acontecer três vezes por semana, após a visita da inspetora às enfermarias onde o interno 
se encontrava. Os alunos receberiam gratificação financeira e deveriam coadjuvar os empregados do estabelecimento no serviço ${ }^{(9)}$.

O ensino era realizado basicamente por meio do estágio, que também garantia mão de obra ao estabelecimento de saúde ${ }^{(9)}$. Em muitas localidades, quando o grupo de professores e estudantes adentravam a instituição de saúde, os funcionários eram deslocados para outras tarefas, deixando a assistência de enfermagem acargo da escola ${ }^{(29)}$.

Em 1923, o Decreto $n^{\circ} 16.300$ aprovou o regulamento do Departamento Nacional de Saúde Pública (DNSP), que criou a Escola de Enfermeiras do DNSP, cujo objetivo era educar enfermeiras profissionais destinadas aos serviços sanitários públicos e aos trabalhos gerais ou especializados dos hospitais e clínicas privadas. Esse decreto, então, apresentou o $\mathbf{2}^{\mathbf{0}}$ modelo de currículo para as escolas de Enfermagem no Brasil. O curso era realizado em dois anos e quatro meses e as aulas teóricas e práticas deveriam ser realizadas concomitantemente. No estágio, denominado então de "estágio de ensaio", as estudantes trabalhavam no hospital por oito horas diárias e assumiam toda a assistência hospitalar ${ }^{(10)}$.

Na sequência, por meio do Decreto n 20.109 a Escola de Enfermeiras Anna Nery, agora modelo de formação a ser seguido no país, determina que só poderia usar o título de enfermeira diplomada aquela cujo diploma fosse registrado no DNSP, órgão responsável pela fiscalização dos currículos. O ensino passa a ser realizado por enfermeiras diplomadas, afastando aquelas que não possuíam formação oficial. O documento não determina claramente o tempo destinado às práticas de estágio ${ }^{(11)}$.

Em 1932, o Decreto ${ }^{\circ} 21.141$ reconheceu a formação de enfermeiras e enfermeiros militares formados pela Cruz Vermelha Brasileira. O documento apresentava um currículo em que a formação deveria acontecer em duas partes: a primeira por meio de aulas teóricas e práticas; e a segunda, denominada "ensino de aplicação", efetuada por estágios sucessivos nos serviços clínicos e laboratoriais, dando ao estágio um papel fundamental na formação profissional. Tal currículo se restringia à formação de enfermeiras militares ${ }^{(12)}$. Passados 16 anos, em 1948, o ensino de Enfermagem da Cruz Vermelha foi equiparado ao padrão Anna Nery, por meio do Decreto $n^{\circ} 24.768^{(13)}$.

Até aquele momento não havia distinção oficial entre a formação de enfermeiras de nível superior e de nível técnico. Em 1949, a Lei n 775 separou o Curso de Enfermagem Superior do Curso de Auxiliar de Enfermagem, e a formação de enfermeiro passou a ser realizada em 36 meses, incluindo as práticas. A graduação em Enfermagem foi para a universidade. Neste momento, os cursos de graduação em Enfermagem passam a precisar de autorização do Governo Federal para o seu funcionamento ${ }^{(14)}$.

A primeira Lei de Diretrizes de Bases para a Educação Nacional foi fixada por meio da Lei $n^{\circ} 4.024$. O Governo Federal passou a regulamentar a formação profissional de enfermeiros ao estabelecer que os currículos mínimos para os cursos de graduação viriam do Conselho Federal de Educação, mas não apresentou, nesse momento, a proposta curricular a ser seguida ${ }^{(15)}$.

No ano seguinte, o Parecer $n^{\circ} 271$ determinou que a formação profissional de Enfermagem não mais teria a Escola Anna Nery como padrão, passando para oConselho Federal de Educação a competência de estabelecer o currículo mínimo, sendo esse o $3^{\mathbf{0}}$ modelo de currículo oficial no Brasil ${ }^{(16)}$.

Neste currículo, o curso de graduação em Enfermagem estava dividido em duas partes, sendo a primeira denominada Curso Geral, com duração de três anos, e forte caráter curativista e hospitalocêntrico. Na sequência, o estudante poderia optar pelo Curso de Enfermagem em Saúde Pública ou pelo Curso de Enfermagem Obstétrica, cada um deles com duração de um ano. Em relação aos estágios, houve a redução da carga horária de 40 horas semanais ${ }^{(11)}$ para 20 horas semanais e os docentes deveriam permanecer no campo apenas durante o período de estágio ${ }^{(16)}$.

Em 1968, o Governo Federal fixou normas de organização e funcionamento do ensino superior em geral, determinando que este passasse a atender também às mudanças do mercado de trabalho, fomentando a articulação ensino-serviço ${ }^{(17)}$. Como o processo ensino-aprendizagem era sistematizado por enfermeiras docentes, reduziu-se a participação dos profissionais dos serviços na organização e implementação das atividades curriculares, o que colaborou para acentuar o distanciamento entre instituição de saúde e de ensino(2).

Em 1972, a Resolução n ${ }^{\circ} 4$ do Conselho Federal de Educação estabeleceuum novo currículo mínimo, correspondendo ao $\mathbf{4}^{\circ}$ modelo de currículo para a formação de enfermeiros no Brasil. Segundo o art. 
$9^{\circ}$ dessa proposta, na modalidade geral de formação de Enfermeiro e em todas as habilitações, seria exigido o Estágio Curricular Supervisionado (ECS), surgindo essa denominação pela primeira vez. Tal atividade deveria ocorrer em hospitais e outros serviços médico-sanitários, com carga horária superior a um terço da correspondente à parte profissionalizante do currículo, e distribuída durante todo o transcurso do período de formação ${ }^{(18)}$.

Para resguardar, de forma oficial, que os estudantes não fossem utilizados como mão de obra barata, em 1977, foi promulgada a Lei $\mathrm{n}^{\circ} 6.494$, a $1^{\mathrm{a}}$ lei deestágio. Essa lei trazia a conceituação clara da intencionalidade dos estágios na formação de nível médio e superior. Estes deveriam propiciar a complementação do ensino e da aprendizagem e serem planejados, executados, acompanhados e avaliados em conformidade com os currículos, programas e calendários escolares, a fim de se constituírem em instrumentos de integração, em termos de treinamento prático, de aperfeiçoamento técnico-cultural, científico e de relacionamento humano ${ }^{(19)}$.

Embora houvesse tensões acerca do papel do estágio na formação profissional, os cursos de graduação em Enfermagem estavam voltados a atender as necessidades do mercado de trabalho, pois se encontravam fortemente organizados para a atenção terciária, à época, sem relação direta com as políticas públicas de saúde então adotadas no país.A falta de aproximação da formação profissional com os objetivos do sistema de saúde contribuiu para o despreparo dos futuros enfermeiros para atender às necessidades de saúde emergentes ${ }^{(30)}$.

Foi somente com a promulgação da Lei ${ }^{\circ}$ 8080, de 1990, que se garantiu a ordenação da formação profissional em saúde alinhando o Sistema de Educação e o Sistema de Saúde ${ }^{(20)}$.

Para atender à nova lógica de saúde, um novo currículo se fez necessário. O $5^{\circ}$ modelo de currículo foi estabelecido em 1994 e, nessa proposta, o ECS foi reafirmado como estratégia fundamental de articulação teoria-prática e de aproximação ensino-serviço. Segundo a Portaria $\mathrm{n}^{\circ} 1721$ do Ministério da Educação e do Desporto, além do conteúdo teórico e prático, os cursos de Enfermagem ficariam obrigados a incluir no currículo o ECS em hospitais, ambulatórios e rede básica de serviços de saúde. O ECS seria desenvolvido sob supervisão docente com a efetiva participação do enfermeiro dos serviços de saúde onde se desenvolveriam os estágios. O documento enfatizava que o ECS deveria ser realizado em dois semestres letivos, sem menção da carga horária total(21).

Em 1996, o Governo Federal abriu a formação acadêmica de nível médio e superior para a iniciativa privada, por meio da nova Lei de Diretrizes e Bases para a Educação Nacional ${ }^{(22)}$. Tal medida estimulou a criação desenfreada de cursos de graduação, o que possibilitou o maior acesso da população à formação superior pelo aumento do número de vagas, mas, ao mesmo tempo, contribuiu para a redução na qualidade da formação.

O $6^{\circ}$ e último modelo de currículo foi estabelecido em 2001, quando o CNE instituiu as Diretrizes Curriculares Nacionais (DCN) para os cursos de Graduação em Enfermagem ${ }^{(7)}$. Nessa proposta, ficou oficializada a implementação e desenvolvimento do ECS pelos cursos de graduação. Entretanto, a participação efetiva dos enfermeiros de campo no planejamento, organização e supervisão dos estudantes trouxe novas demandas às instâncias deliberativas da profissão. A instituição das DCN desencadeou uma série de debates dentro do COFEN e da ABEnacerca, principalmente, da responsabilidade e da intencionalidade do enfermeiro de campo com os estudantes de graduação.

Para garantir essa experiência e, mais uma vez, proteger os estudantes do exercício antecipado do trabalho propriamente profissional, o CNE promulgou a Resolução $n^{\circ} 1$ estabelecendo que toda e qualquer atividade de estágio seria sempre de natureza curricular e supervisionada, assumida pela Instituição de Ensino Superior (IES) e configurando-se em ato educativo ${ }^{(23)}$. Diferentemente do que aconteceu nos modelos anteriores, quando os estudantes eram responsáveis pela assistência de enfermagem, cumpridas em longas jornadas de trabalho, remuneradas ou não, essa resolução determinou que a carga horária do estágio profissional supervisionado não poderia exceder uma jornada diária de seis horas, perfazendo um total de 30 horas semanais.

Para o COFEN, segundo Resolução $n^{\circ} 299$, o planejamento, execução, supervisão e avaliação das atividades seriam de responsabilidade da IES, com a coparticipação do enfermeiro da área cedente do campo de estágio. As unidades selecionadas para as ações formativas deveriam dispor de condições para proporcionar experiência prática na linha de formação, devendo o estudante estar apto ao 
cumprimento do estágio. O órgão representante de classe determina que o enfermeiro das unidades concedentes de ECS não poderia exercer, ao mesmo tempo, as funções próprias naquele serviço e as de supervisor de estágio ${ }^{(24)}$.

O Ministério do Trabalho também declarou seu posicionamento frente à temática ECS com a Lei $\mathrm{n}^{\circ}$ 11788 afirmando que o estágio era um ato educativo escolar supervisionado, devendo, portanto, ser acompanhado efetivamente pelo professor orientador da IES e por um supervisor de campo da parte concedente, respeitando a proporção de até 10 estagiários por profissional ${ }^{(25)}$.

Os debates sobre o tema continuaram. Em 2010, o COFEN emitiu a Resolução $n^{\circ} 371^{(26)}$, esclarecendo o papel do profissional enfermeiro de campo frente à Lei $\mathrm{n}^{\circ} 11.788 / 2008^{(25)}$. Este deveria orientar e supervisionar os estudantes durante o estágio e em quaisquer atividades práticas, participando na formalização e planejamento do estágio.

Tais documentos serviram de pauta para fomentar os debates no $13^{\circ}$ Seminário Nacional de Diretrizes para a Educação em Enfermagem, o que resultou na publicação da Carta de Belém, em $2012^{(31)}$. Em reposta a essa iniciativa, o COFEN instituiu uma comissão para discutir o tema do ECS e, em 2013, emitiu a Resolução $n^{\circ}$ 441. Essa normativa retomou a questão daparticipação do enfermeiro de campo na supervisão de atividade prática e do estágio supervisionado, definindo o que esse órgão entendia por atividade prática e ECS. Segundo o documento, as atividades seriam de competência do enfermeiro docente; por sua vez, o ECS deveria ter acompanhamento efetivo e permanente do professor orientador da IES e doenfermeiro supervisor da parte concedente ${ }^{(27)}$.

O último documento publicado acerca da temática ECS foi a Resolução COFEN $n^{\circ} 539^{(28)}$, que revogou o Art. $1^{\circ}$, inciso II da Resolução COFEN $n^{\circ} 441 / 2013^{(27)}$, que definia oque se entendia porECS. Atualmente não há conceito sobre o que é ECS para aquela autarquia.

Ao longo dessa trajetória, observa-se que houve um avanço no movimento de reflexão acerca dos objetivos educacionais na formação do profissional enfermeiro, e que esse processo se desdobrou em regulamentações, tanto para o ensino quanto para o exercício profissional, ora protegendo os estudantes, ora protegendo os enfermeiros de campo dos desvios de funções educacionais e laborativas. Entretanto, o que se observa, na atualidade, é a existência de um arsenal legislativo muitas vezes divergente, o que tem contribuído para o distanciamento entre o ensino de Enfermagem e a realidade do mundo do trabalho.

O intuito deste trabalho foi elencar fatos históricos que demarcassem a implantação do ECS enquanto atividade pedagógica final da formação de enfermeiros e sua importância para o desenvolvimento do futuro profissional. Ressalta-se que não se trata de um estudo fim, em que se objetivou esgotar todas as legislações vigentes, mas visa apenas colaborar com futuros debates.

\section{CONSIDERAÇÕES FINAIS}

Embora haja disputas entre o campo da formação e o mundo do trabalho, não se trata de forças contrárias, mas de sistemas que se complementam. A formação profissional em Enfermagem visa preparar enfermeiros para a defesa dos conceitos-chave da profissão e para um exercício profissional com autonomia e características próprias, pautado pela lógica da interdisciplinaridade. Esta última só será possível se o estudante vivenciar o mundo real do trabalho, sob a preceptoria de um profissional enfermeiro que atue no campo de estágio, a tutoria de um docente e a orientação de demais profissionais que venham a compor os processos de produção de cuidados em saúde.

O ECS deve se caracterizar como espaço oportuno e de imersão do estudante no campo de trabalho, por meio da socialização de vivências, com embasamento científico, atuação ética e desempenho prático vivido entreos profissionais já graduados.

As disputas e tensões que cercam a implementação e o desenvolvimento do ECS nos cursos de graduação em Enfermagem evidenciam o movimento real e natural que os atores sociais envolvidos provocam e assim constroem a história. Esses movimentos provocam e fomentam os processos de mudanças nas formas de se ensinar e aprender enfermagem.A história põe em evidência tensões e obstáculos e auxilia no processo de evolução, estimulando a superação permanente de dificuldades e 
barreiras encontradas na melhoria de processos de ensino.

Acredita-se que estas reflexões históricas possam servir de subsídio para fomentar discussões entre os atores sociais que compõe o ensino de enfermagem, mobilizando desde os profissionais que participam da elaboração de políticas educacionais, até aqueles que as colocam em prática. A ausência de compreensão clara dos conceitos e intencionalidades que envolvem as atividades executadas nos serviços de saúde, sejam elas práticas clínicas ou ECS, podem comprometer a qualidade do ensino profissional de enfermeiros e consequentemente a efetivação do próprio Sistema de Saúde Brasileiro.

\section{AGRADECIMENTO}

A pesquisa de doutorado foi realizada com auxílio de Bolsa de Estudos do Programa de Demanda Social - Coordenação de Aperfeiçoamento de Pessoal de Nível Superior - CAPES (Portaria Conjunta CAPES/CNPQ N 1, de 15 de julho de 2010).

\section{REFERÊNCIAS}

1. Sales PRS, Marin MJS, Silva Filho CR. Integração academia-serviço na formação de enfermeiros em um hospital de ensino. Trab. educ. saúde. [Internet]. 2015 [acesso em 2017 fev 30];13(3). Disponível em:http://dx.doi. org/10.1590/1981-7746-sip00057.

2. Costa LM, Germano RM. Estágio curricular supervisionado na Graduação em Enfermagem: revisitando a história. Rev. bras.enferm. [Internet]. 2007 [acesso em 2017 fev10];60(6). Disponível em: http://dx.doi.org/10.1590/ S0034-71672007000600016.

3.Marran AL, Lima PG, Bagnato MHS. As políticas educacionais e o estágio curricular supervisionado no curso de graduação em enfermagem. Trab. educ. saúde. [Internet]. 2015 [acesso em 2017 abr30];13(1). Disponível em: http://dx.doi.org/10.1590/1981-7746-sip00025.

4. Pinto TR, Cyrino EG. Com a palavra, o trabalhador da Atenção Primária à Saúde: potencialidades e desafios nas práticas educacionais. Interface (Botucatu). [Internet]. 2015 [acesso em 2017 fev17];19(Suppl1). Disponível em: http://dx.doi.org/10.1590/1807-57622014.0991.

5. Brasil. Constituição da República Federativa do Brasil. Brasília: Senado Federal; 1988.

6. Werneck MAF, Senna MIB, Drumond MM, LSD.Nem tudo é estágio: contribuições para o debate. Ciênc. Saúde Coletiva. [Internet]. 2010 [acesso em 2017 fev10];15(1). Disponível em: http://www.scielosp.org/scielo. php?script=sci_arttext\&pid=S1413-81232010000100027\&lng=en.

7. Conselho Nacional de Educação. Câmara de Educação Superior. Resolução CNE/CES n. 3, de 7 de novembro de 2001. Institui Diretrizes Curriculares Nacionais do Curso de Graduação em Enfermagem. Brasília: Ministério da Educação e Cultura; 2001.

8. Oguisso T, Campos PFS, Freitas GF. Pesquisa em história da enfermagem. 2.ed. Barueri: Manole; 2011.

9. Brasil. Decreto n. 791, de 27 de setembro de 1890: cria no Hospício Nacional de Alienados uma escola profissional de enfermeiros e enfermeiras. Câmara dos Deputados, [Internet]. 27 set. 1980 [acesso em 2017 mar 10]. Disponível em: http://www2.camara.leg.br/legin/fed/decret/1824-1899/decreto-791-27-setembro-1890503459-publicacaooriginal-1-pe.html.

10. Brasil. Decreto n. 16.300, de 31 de dezembro de 1923:cria a Escola de Enfermagem, vinculada ao Departamento Nacional de Saúde Pública. Casa Civil [Internet].31 dez 1923 [acesso em 2017 mar 10]. Disponível em: http://www. planalto.gov.br/ccivil_03/decreto/1910-1929/d16300.htm.

11. Brasil. Lei n. 20.109, de 15 junho de 1931. Regula o exercício de enfermagem no Brasil e fixa, as condições para a equiparação das escolas de enfermagem. Diário Oficial da União, Brasília, 15 jun. 1931.

12. Brasil. Decreto n. 21.141, de 10 de março de 1932: aprova o regulamento para a organização dos enfermeiros do exército. Brasília: Câmera dos Deputados, [Internet] 10 mar 1932 [acesso em2017 mar 20]. Disponível: http:// 
www.planalto.gov.br/ccivil_03/decreto/1930-1949/D21141.htm.

13. Brasil. Decreto n. 24.768, de 6 de abril de 1948: concede equiparação à Escola de Enfermagem da Cruz Vermelha Brasileira.Brasília:Câmera dos Deputados, [Internet] 6 abr 1948 [acesso em 2017 mar 20].Disponível em: http:// www2.camara.leg.br/legin/fed/decret/1940-1949/decreto-24768-6-abril-1948-411018-publicacaooriginal-1-pe. html.

14. Brasil.Lei n. 775, de 6 de agosto de 1949. Dispõe sobre o ensino de enfermagem no país e dá outras providências. Diário Oficial da República Federativa do Brasil, Brasília, 6 ago. 1949.

15. Brasil. Lei n. 4024, de 20 de dezembro de 1961. Fixa as Diretrizes e Bases da Educação Nacional. Diário Oficial da República Federativa do Brasil, Brasília, 20 dez. 1961.

16. Brasil. Parecer n. 271/62, de 19 de outubro de 1962. Dispõe sobre o currículo mínimo do curso de enfermagem. Ministério da Saúde (BR). Fundação Serviços de Saúde Pública. Enfermagem, legislação e assuntos correlatos, Rio de Janeiro, 19 out. 1972.

17. Brasil. Lei n. 5540 de 28 de novembro de 1968. Fixa normas de organização e funcionamento do ensino superior e sua articulação com a escola média, e dá outras providências. Diário Oficial da República Federativa do Brasil, Brasília, 28 nov. 1968.

18. Conselho Federal de Educação. Resolução n. 04-72, de 25 de fevereiro de 1972. Rev. bras. enferm. [internet]. 1973 [acesso em 2017 mar 17];26(4-5). Disponível em: http://dx.doi.org/10.1590/0034-716719730005000017.

19. Brasil. Lei n. 6.494, de 7 de dezembro de 1977. Dispõe sobre os estágios de estudantes de estabelecimentos de ensino superior e de ensino profissionalizante de $2^{\circ}$ grau e supletivo e dá outras providências. Diário Oficial da República Federativa do Brasil, Brasília,7 dez. 1977.

20. Ministério da Saúde (BR). Lei n. 8.080, de 19 de setembro de 1990. Dispõe sobre as condições para a promoção, proteção e recuperação da saúde, a organização e o funcionamento dos serviços correspondentes e dá outras providências. Conselho Nacional da Saúde, Brasília, 19 set. 1990.

21. Brasil. Portaria n. 1721, de 15 de dezembro de 1994. Fixa os conteúdos mínimos e duração do curso de graduação em enfermagem. Gabinete do Ministro. 1994 dez. 15; Seção 1.p 19.801. Brasil. Brasília: Gabinete do Ministro; 1994.

22. Brasil. Lei n. 934 de 20 de dezembro de 1996. Estabelece as diretrizes e bases da educação nacional. Diário Oficial da República Federativa do Brasil, Brasília, 20 dez. 1996.

23. Ministério da Educação (BR). Resolução CNE/CEB n. 1, de 21 de janeiro de 2004. Estabelece Diretrizes Nacionais para a organização e a realização de estágio de alunos da educação profissional e do ensino médio, inclusive nas modalidades de educação especial e de educação de jovens e adultos. Brasília: Diário Oficial da União; 2004.

24. Conselho Federal de Enfermagem. Resolução n. 299/2005. Dispõe sobre indicativos para a realização de estágio curricular supervisionado de estudantes de enfermagem de graduação e do nível técnico da educação profissional. Brasília: COFEN;2005.

25. Brasil. Lei n. 11.788, de 25 de setembro de 2008. Dispõe sobre o estágio de estudantes. Diário Oficial da República Federativa do Brasil, Brasília, 25 set. 2008.

26. Conselho Federal de Enfermagem. Resolução n. 371, de 08 de setembro de 2010. Dispõe sobre a participação do enfermeiro na supervisão de estágio de estudantes dos diferentes níveis da formação profissional em enfermagem. Brasília:COFEN; 2010.

27. Conselho Federal de Enfermagem. Resolução n. 441, de 15 de maio de 2013. Dispõe sobre participação do enfermeiro na supervisão de atividade prática e estágio supervisionado de estudantes dos diferentes níveis da formação profissional de enfermagem. Brasília: COFEN; 2013.

28. Conselho Federal de Enfermagem. Resolução n. 539, de 07 de abril de 2017. Revoga o inciso II, do artigo $1^{\circ}$ da Resolução Cofen n. 441/2013. Brasília: COFEN; 2017.

29. Friedländer, MR. Como supervisionar um estágio de enfermagem. $1^{\mathrm{a}}$ ed. São Paulo: Editora Green Forest do Brasil; 2005. 
30. Chaves VLJ. Expansão da privatização/mercantilização do ensino superior brasileiro: a formação dos oligopólios. Educ. Soc. [Internet]. 2010[acesso em2017 maio 10];31(111). Disponível em: http://dx.doi.org/10.1590/ S0101-73302010000200010

31. Associação Brasileira De Enfermagem (ABEn). Carta de Belém para a educação em enfermagem brasileira. In: 13 Seminário Nacional de Diretrizes para a Educação em Enfermagem: 2012 Ago/Set. Brasília, Brasil. Brasilia: ABEn; 2012. 